\title{
Secondary neoplasms of the urinary bladder-clinical management and oncological outcomes
}

\author{
Omar El-Taji ${ }^{1 \wedge}$, Abdullah Al-Mitwalli ${ }^{1}$, Farhan Malik², Samita Agarwal ${ }^{3}$, Andrew Gogbashian ${ }^{4}$, \\ Rob Hughes ${ }^{5}$, Nikhil Vasdev ${ }^{1,6}$, Anand Sharma ${ }^{5}$ \\ ${ }^{1}$ Department of Urology, Lister Hospital, East and North Herts NHS Trust, Stevenage, SG1 4AB UK; ${ }^{2}$ Imperial College Business School, London, \\ UK; ${ }^{3}$ Department of Histopathology, Lister Hospital, East and North Herts NHS Trust, Stevenage, SG1 4AB, UK; ${ }^{4}$ Department of Radiology, \\ Mount Vernon Cancer Centre, Paul Strickland Scanner Centre, Northwood, HA6 2RN, UK; ${ }^{5}$ Department of Medical Oncology, Mount Vernon \\ Cancer Centre, Northwood, HA6 2RN, UK; ${ }^{6}$ School of Life and Medical Sciences, University of Hertfordshire, Hatfield, UK \\ Contributions: (I) Conception and design: O El-Taji, A Sharma, N Vasdev; (II) Administrative support: A Al-Mitwalli; (III) Provision of study materials \\ or patients: S Agarwal, R Hughes, A Gogbashia; (IV) Collection and assembly of data: O El-Taji, S Agarwal; (V) Data analysis and interpretation: O \\ El-Taji, F Malik; (VI) Manuscript writing: All authors; (VII) Final approval of manuscript: All authors. \\ Correspondence to: Mr. Omar El-Taji. Urology Registrar, Lister Hospital, East \& North Hertfordshire NHS TrustCoreys Mill Lane Stevenage, SG1 \\ 4AB, UK. Email: Omar.el-taji@nhs.net.
}

Background: Secondary neoplasms of the bladder account for $4.5 \%$ of all bladder neoplasms however there is limited literature reporting management and survival. This is the largest single centre series presented in current literature with long term oncological follow up.

Methods: This is a single institutional, retrospective cohort study of patients with a histological diagnosis of a secondary bladder neoplasm from January 2007 to December 2017 ( $n=40)$. Prognostic variables examined included age at diagnosis, histology, disease free survival and treatment. Kaplan-Meier analysis was used to calculate survival. We used multiple regression analysis to identify the most significant treatments for each population group in terms of their survival.

Results: Twenty-one patients were male (53\%) with a median age of 68 and 19 were female (47\%) with a median age of 64 . The most common secondary neoplasms and their median survival were prostate [12 patients (30\%), 446 days], colorectal [9 patients (23\%), 403 days], ovarian [5 patients (13\%), 369 days], cervical [ 4 patients (10\%), 148 days], breast [3 patients ( $8 \%$ ), 241 days], lymphoma [3 patients ( $8 \%$ ), 145 days], gastric [2 patients (5\%), 66 days], and renal [2 patients (5\%), 854 days]. Those receiving treatment following a secondary diagnosis demonstrated statistical significance in survival for colorectal (surgery $\mathrm{P}=0.013$ ), prostate (radiotherapy $\mathrm{P}=0.0012$ and hormonal therapy $\mathrm{P}=0.004$ ) and ovarian cancer (chemotherapy $\mathrm{P}=0.00002)$.

Conclusions: Prognosis and treatment depends upon the primary neoplasm. There is some survival benefit in well selected patients receiving treatment following a diagnosis of a bladder secondary.

Keywords: Bladder cancer; metastatic cancer; survival; secondary neoplasm

Submitted May 28, 2020. Accepted for publication Dec 23, 2020.

doi: $10.21037 /$ tau-20-955

View this article at: http://dx.doi.org/10.21037/tau-20-955

^ ORCID: 0000-0002-1788-3669. 


\section{Introduction}

The urinary bladder appears to be the second most common site to be involved in secondary neoplasms to the genitourinary tract following the kidney (1). This accounts for $4.5 \%$ of all bladder neoplasms, and is often misdiagnosed, due to lack of any symptoms, i.e., haematuria (2).

Secondary neoplasms to the urinary bladder can be a result of direct extension from another pelvic malignancy, metastasis from distant organs, or hematopoietic malignancies as part of more extensive disease (3). The majority of secondary bladder tumours come from direct spread, as demonstrated by Velcheti et al. and Morichetti et al. $(4,5)$. A smaller proportion of secondary neoplasms of the bladder are secondary to metastatic deposits, most commonly the breast, stomach, lung and skin $(6,7)$. In some circumstances the histological appearances may be characteristic but many secondary tumours, particularly adenocarcinomas, can pose diagnostic difficulty $(8,9)$. There is limited literature available reporting, the management and survival of secondary neoplasms to the bladder and of those available these are early studies and/or of small series (10-12). Moreover the majority of published data has been from autopsy which gives us incomplete details of disease management.

The available data suggests the most common primary sites of tumour origin that metastasise to the bladder are colon, prostate, rectum and cervix. These often reflect the most common histological subtype of each cancer origin $(2,4-7,12)$. Breast cancer primaries metastasising to the bladder have the most data on management and survival however these studies vary on survival ranging from 1 month to over 5 years $(10,13)$. While it has been reported that radiotherapy should be considered to provide local disease control, treatment often involves a combination of chemotherapy and hormonal treatment (especially in prostate and breast cancer) (14). Partial and complete cystectomy have been rarely reported (4).

We aim to report our institution's experience of secondary neoplasms of the bladder from various primary sites and the surgical and oncological management of these patients in addition to their survival. This is the largest single centre series presented in current literature with long term oncological follow up. We anticipate that this will help clinicians better understand the clinical presentation and management of patients with secondary neoplasms to the bladder.

We present the following article in accordance with the
STROBE reporting checklist (available at http://dx.doi. org/10.21037/tau-20-955).

\section{Methods}

\section{Study population}

This is a single institutional, retrospective cohort study. The study was conducted in accordance with the Declaration of Helsinki (as revised in 2013). The study was approved by the institutional review board (Lister Hospital, \#17149) and individual consent for this retrospective analysis was waived. We retrieved data from all patients who had secondary neoplasms to the bladder treated at our centre from January 2007 to December 2017. We defined these as tumours involving the urinary bladder via direct spread from adjacent advanced tumours, or distant metastasis (including from hematopoietic malignancies). We ensured all patients had a diagnosis of secondary bladder neoplasm either by a histological appearance comparable to that of a primary tumour or that the histological features were incompatible with a urothelial origin. Furthermore the secondary tumour must have demonstrated invasion into the muscularis and/ or lamina propria. Excluded from our study were patients with primary atypical bladder cancer which included primary squamous cell carcinoma, primary adenocarcinoma, sarcomatoid carcinoma and neuroendocrine tumours. We identified 40 patients with a diagnosis of secondary tumour of the urinary bladder over a 10 -year period. Fiftyfour cases were excluded from our study due to atypical histology. All cases were diagnosed by either transurethral resection of bladder tumour (TURBT) or bladder biopsy.

\section{Measures and outcome assessments}

Prognostic variables examined included age at diagnosis, sex, histology, clinical presentation, disease free survival and treatment. The treatments we examined included surgery, radiotherapy, chemotherapy and/or hormonal therapy prior to a diagnosis of secondary neoplasm as well as surgery, chemotherapy, radiotherapy and/or hormonal treatment following a diagnosis of secondary bladder neoplasm. Patient selection and variables were obtained through reviewing clinical history, histopathology, history of lymphovascular spread, radiological support of nonbladder origin, and Immunohistochemical analysis. KaplanMeier analysis was used to calculate survival. Our primary outcome measure was overall survival. Survival was defined 
Table 1 Patient demographics with those known to have history of a non-bladder primary malignancy

\begin{tabular}{lcc}
\hline & Male $(\mathrm{n}=21)$ & Female $(\mathrm{n}=19)$ \\
\hline Age at presentation & $68(40-90)$ & $64(48-80)$ \\
Known Primary malignancy & 10 & 11 \\
\hline
\end{tabular}

as number of days from secondary diagnosis of a bladder neoplasm to death or to our censorship date $\left(19^{\text {th }}\right.$ May 2019). We followed up all patients until the censorship date. Information bias was reduced by searching through both pathological and oncological data.

\section{Statistical analyses}

Prism 6 (GraphPad Software, Inc., San Diego, CA) was used for graphical representation and statistical analysis. A two tailed t-test was used to determine the relationship amongst categorical variables. We used GRETL (Gnu Regression, Econometrics and Time-series Library 64bit) software to create a multiple regression analysis using stepwise backwards elimination to build models which identified the most significant treatments for each population group in terms of their survival. We defined the optimal model as the one with $\mathrm{P}$ values lower than our significance $95 \%$ ( $\mathrm{P}$ value $<0.05$ ). We estimated overall survival using the Kaplan-Meier method. All statistical tests were two-sided by default, and the significance level was set to 0.05 unadjusted for multiple comparisons.

\section{Results}

We identified 40 patients with a diagnosis of secondary tumour of the urinary bladder. All 40 patients who were included in our study, completed follow-up, and were analysed. In the study population, average age at presentation was 68 (40-90) in men and $64(48-80)$ years in women, with $50 \%$ of these patients having history of a nonbladder primary malignancy (Table 1). The median survival of our patient cohort from diagnosis of a bladder secondary neoplasm was 272 days (Figure 1). Complete patient management as well as individual survival is detailed in the attached Appendix 1, individual tumour characteristics are mentioned below.

There were 12 patients with secondary bladder neoplasms of prostatic origin with histological analysis demonstrating adenocarcinoma. The median age was 74 (51-90) and 8 patients were diagnosed at cystoscopy

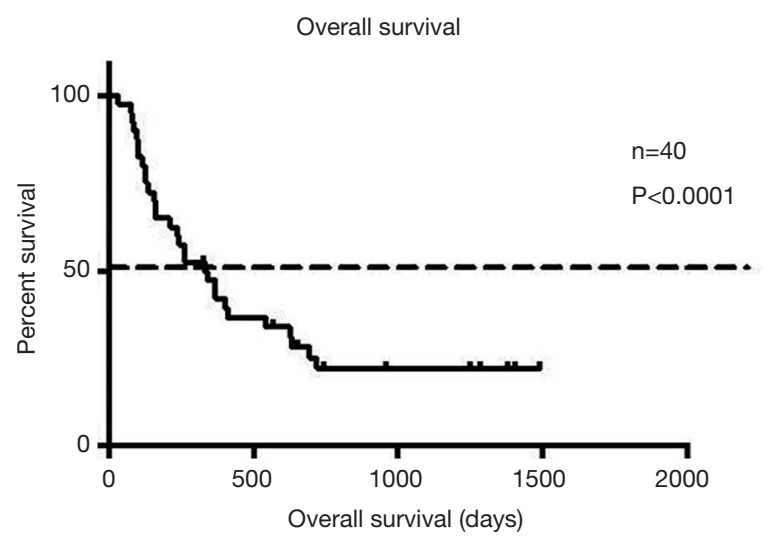

Figure 1 Kaplan-Meier curve of overall survival for all 40 patients following diagnosis of a secondary neoplasm to the urinary bladder.

for urinary symptoms, with 1 patient diagnosed at transurethral resection of prostate (TURP) performed for lower urinary tract symptoms with no previous history of malignancy. 3 patients had imaging suggestive of a bladder tumour and 4 patients had a previous history of prostate adenocarcinoma. The median time from primary to secondary diagnosis was 981 days (948-4,748 days). All specimens exhibited carcinoma infiltrating the muscularis propria. Immunohistochemistry analysis demonstrated positivity for PSA and PSAP confirming the prostatic origin of the specimen. AMACR 63 and CK5 favoured the diagnosis of prostatic adenocarcinoma. Of these patients $5(42 \%)$ continue on treatment for prostate cancer. The median survival for our patients was 446 days (Table 2). Our results show that fewer days from primary (prostate) to secondary (bladder) diagnosis $(\mathrm{P}=0.0013)$, patients receiving radiotherapy after diagnosis of a secondary bladder neoplasm $(\mathrm{P}=0.0012)$, and those receiving hormonal therapy after secondary diagnosis $(\mathrm{P}=0.004)$ had the most significant survival advantage. There was no significance in survival of those patients undergoing chemotherapy following their diagnosis (Table 3).

A total of 9 patients with bladder metastases were from a colorectal primary with a median age of $62(40-75)$ with the histological diagnosis of adenocarcinoma. One patient was 
Table 2 The distribution of the primary foci of metastatic tumour's to the bladder and their survival

\begin{tabular}{|c|c|c|c|c|c|}
\hline Primary disease & Age at diagnosis & Gender M:F & Tumour histology & Biopsy/TURBT & $\begin{array}{l}\text { Overall survival } \\
\text { (days) }\end{array}$ \\
\hline Prostate & $74(56-90)$ & - & Adenocarcinoma & All & 446 \\
\hline Colorectal & $60(40-75)$ & $6: 3$ & Adenocarcinoma & All & 403 \\
\hline Ovarian & $65(53-74)$ & - & $\begin{array}{l}\text { Mucinous papillary } \\
\text { carcinoma }\end{array}$ & All & 369 \\
\hline Breast & $65(61-68)$ & - & Ductal carcinoma & All & 241 \\
\hline Lymphoma & $80(78-82)$ & $1: 2$ & $\begin{array}{l}\text { Diffuse large B cell } \\
\text { lymphoma }\end{array}$ & All & 145 \\
\hline
\end{tabular}

Table 3 Survival variables for the primary malignancies which produced statistical significance $(\mathrm{P}<0.05)$. Breast, Lymphoma, Renal and Gastric cancers however produced ZERO statistical significant for any variable

\begin{tabular}{|c|c|c|c|c|c|c|}
\hline Primary & \multicolumn{6}{|c|}{ Survival variables ( $\mathrm{P}$ value) } \\
\hline Prostate & 0.0013 & 0.0012 & 0.004 & - & - & 0.12 \\
\hline Ovarian & 0.54 & - & - & 0.75 & - & 0.00002 \\
\hline Cervical & 0.62 & - & - & 0.043 & - & - \\
\hline
\end{tabular}

diagnosed following cystoscopy for haematuria, 1 patient following an acute presentation with abdominal pain whilst the rest were diagnosed following suspicious radiological findings. Five patients had a known prior history of colorectal adenocarcinoma and 1 patient presented with a vesico-vaginal fistula. The median time from primary to secondary diagnosis was 531 days $(62-2,979)$. All specimens exhibited carcinoma infiltrating the muscularis propria. Immunohistochemistry analysis demonstrated in the vast majority of cases, positivity for CK20, CK7 and CDX2. K-Ras sequencing results were available for 2 patients, both of which demonstrated a mutated gene. The median survival for our patients was 403 days (Table 2). Our results show patients undergoing surgery at initial diagnosis
$(\mathrm{P}=0.03)$ and following diagnosis of a bladder secondary $(\mathrm{P}=0.013)$ had a survival advantage. Moreover, patients who received radiotherapy following diagnosis of a bladder secondary had an improved survival $(\mathrm{P}=0.045)$. Days from primary to secondary diagnosis as well as patients receiving chemotherapy following their secondary diagnosis had no impact in their survival (Table 3).

We identified 5 patients with secondary bladder neoplasms of ovarian origin with a median age of 65 (53-74). One patient was diagnosed following an episode of frank haematuria requiring hospitalisation and 1 patient had acutely presented with abdominal pain. The remainder were diagnosed following radiological investigation. Two patients had a known primary of ovarian carcinoma diagnosed within 
the last 10 years. Serous papillary carcinoma was seen in 4 patients and 1 patient had a mucinous papillary carcinoma. The median time from primary to secondary diagnosis was 111 days (143-411). All bladder biopsy's or TURBT specimens exhibited carcinoma infiltrating the muscularis propria. Immunohistochemistry analysis demonstrated positivity for CK7, WT-1 and Ca-125. The median survival for our patients with ovarian primary was 369 days (Table 2). Our results demonstrate that the most significant survival advantage came when patients received chemotherapy following diagnosis of a bladder secondary neoplasm $(\mathrm{P}=0.0002)$. Days from primary to secondary diagnosis and patients undergoing surgery at initial diagnosis of ovarian cancer did not improve survival (Table 3).

There were 4 patients with cervical origin of secondary bladder neoplasms with a median age of 60 (49-71), the primary histology being squamous cell carcinoma. One patient presented with haematuria, the rest were identified radiologically. Two patients had been diagnosed with cervical cancer within the last 10 years. The median time from primary to secondary diagnosis was 141 days (241-324). All specimens exhibited carcinoma infiltrating the muscularis propria. Immunohistochemistry analysis of the bladder specimens displayed positivity for CK5, 7 and P63 and negativity for CK20 confirming the cervical origin of the tumours. The median survival for patients with cervical cancer was 148 days (Table 2). Our results demonstrate that patients receiving surgery at initial diagnosis had an improved overall survival $(\mathrm{P}=0.043)$. Fewer days from primary to secondary diagnosis did not have a statistically significant effect on survival (Table 3).

We identified 3 patients with secondary bladder neoplasms of breast origin (invasive ductal carcinoma) with a median age of 65 (61-68). All patients presented with urinary symptoms (haematuria and urinary retention). The median time from primary to secondary diagnosis was 1,211 days (481-1,869). Immunohistochemistry analysis demonstrated positivity for CK7, CK8/18, ER, PR and CEA and a high proliferation rate of Ki67. The median survival for our patients was 241 days (Table 2).

3 patients were shown to have a secondary bladder neoplasm of lymphocytic origin (diffuse large B cell lymphoma) with a median age of 80 (78-82). All three patients presented with urinary symptoms (recurrent UTI and haematuria) and had a prior diagnosis of lymphoma. The median time from primary to secondary diagnosis was 368 days (146-431). The infiltrating cells were positive for CD45, CD20 and bcl-2 throughout. A high ki-67 proliferative marker was also noted in all specimens. The median survival for our patients was 145 days (Table 2).

We identified 2 patients with secondary bladder tumours of renal origin (clear cell carcinoma) with a median age 72 (59-85). One patient presented following a routine surveillance scan whilst the other patient had presented with a 3-month history of haematuria. Both patients had a prior nephrectomy. One patient had an existing diagnosis of G3 pT1 bladder cancer. The median time from primary to secondary diagnosis was 2,306 days $(744-3,868)$. Both specimens demonstrated a tumour immunoprofile which was positive for CK7, P53, AMACR63 and CEA. The median survival for our patients was 854 days (Table 2).

There were 2 patients with a histological diagnosis of secondary bladder neoplasm of gastric origin with a median age of 56 (54-59), Histology demonstrated an intestinal type adenocarcinoma of the stomach. Both patients presented acutely, with severe abdominal pain, and bilateral hydronephrosis. Neither patient had a previous history of malignancy however their presentation was a consequence of widespread metastasis. The specimens demonstrated a well differentiated tubular adenocarcinoma. The median survival for our patients was 66 days (Table 2).

\section{Discussion}

To our knowledge this is the first comprehensive retrospective study of clinical profile of secondary neoplasms to the bladder. Previously reported studies (Bates, Abrams, Morichetti, Melicow, Sheehan, Xiao, Ganem) (2-3,5-7,10,15), have been a combination of clinical and autopsy cases, with primary focus being the pathological characteristic of the tumours, and sparse evidence of clinical outcomes. Although the age at presentation of bladder cancer is $65-70$, secondary metastasis of the bladder is seen at 68 in men and 64 years in women, as seen in our study (16).

Amongst our cohort, prostate cancer has been the highest contributor to secondary bladder neoplasms and prognosis of these patients has been better as oppose to other primaries. This could also primarily reflect current treatment outcomes in prostate cancer (17).

The longest duration between diagnosis of primary cancer and metastases was in patients with prostate and breast cancer, and shortest in cervical and ovarian cancer. In previously published series of secondary bladder cancer, the highest incidence was of colorectal cancer in both sexes, and the second most common were gynecological malignancies in women and prostate cancer in men (18). 
When comparing the different sites of primary cancers, renal cell carcinoma appears to be the site with the longest survival data as compared to the others (854 days), followed by prostate (446 days). Furthermore, we found that other sites with a survival more than 365 days were colorectal and ovarian cancers.

An important finding in this study is the predilection of histological subtype of various primary sites and their survival as compared to the published data. Invasive ductal cancer is the chief histologic subtype in breast primary, with a median age of 65 , and average survival of 241 days, which is in contrast to the published data of metastatic breast cancer (900 days) (19). The histologic subtype in renal, gastric, cervical, prostate and colorectal were in keeping with the typical common subtype of tumours seen in these cancers.

In patients with ovarian cancer as the primary, the papillary histology was seen in $80 \%$ of the tumours, with the remaining subtype being mucinous papillary carcinoma. Survival in our patients with ovarian cancer was 12 months in contrast to stage 4 ovarian cancer with a survival of 33.6 months $(20,21)$. This illustrates the poorer outcomes in bladder metastasis. The prognoses of metastasis to the bladder, depends upon the type of primary, rather than the extent of the metastases.

There are no standard guidelines, to manage patients with secondary bladder cancer, however TURBT is an appropriate procedure, as it not only provides us with diagnostic information, but it is also useful for palliation in advanced disease. Due to the available therapeutic options an accurate diagnosis is essential for the optimal management. In samples with atypical histology, further analysis is advisable through immunohistochemistry to confirm tumour origin. Any patients with new urinary symptoms need to be worked up in order to exclude any bladder lesions (22).

Our major findings were illustrated through examining prognostic variables which had an impact on survival. Length of time between primary and secondary disease was significant in prostate cancer. Those undergoing surgery prior to their secondary diagnosis showed a statistically significant improvement in survival for colorectal and cervical cancer. Those receiving treatment after a secondary diagnosis demonstrated statistical significance in survival for colorectal (surgery), prostate (radiotherapy and hormonal therapy) and ovarian cancer (chemotherapy). Breast, lymphoma renal and gastric cancers however produced zero statistical significant for any variable. This is due to the number of observations (patients) being fewer than the number of variables in question. More data points are required to get any form of correlation.

This study does have its limitations. This was a retrospective, single centre study. The rarity of this diagnosis leads to a small sample size which limits its statistical power and makes it difficult to extrapolate these results. The retrospective nature of this study also introduces bias. We must also consider that in our breast, lymphoma, renal and gastric groups, limited numbers prevented statistically significant results. We would advocate a multicentre study with a larger cohort in order to be better equipped to recommend management. Our results and conclusions will be limited to patients with secondary neoplasms of the bladder and further research into other secondary malignancies will be important to provide comparisons.

\section{Conclusions}

The most common secondary neoplasms of bladder are prostate, colorectal, and of ovarian origin. Outcomes of metastatic cancer to the bladder depend on a variety of factors including location of the primary foci, grade, number and location of the metastatic lesions. With the availability of newer immunotherapeutic options and targeted therapies in solid tumours, it is essential to obtain tissue diagnosis from bladder tumours. Radical surgery (cystectomy) is not advisable, as it will increase morbidity and has a limited role in advanced disease. There is some survival benefit in well selected patients receiving treatment following a diagnosis of a bladder secondary. With life expectancy in metastatic bladder cancer less than a year, and survival in secondary malignancies of bladder more than a year, histological, clinical, radiological and biochemical diagnosis is helpful in guiding appropriate treatment.

\section{Acknowledgments}

Funding: None.

\section{Footnote}

Reporting Checklist: The authors have completed the STROBE reporting checklist. Available at http://dx.doi. org/10.21037/tau-20-955

Data Sharing Statement: Available at http://dx.doi. 
org/10.21037/tau-20-955

Conflicts of Interest: All authors have completed the ICMJE uniform disclosure form (available at http://dx.doi. org/10.21037/tau-20-955). Dr. Sharma reports grants from NIHR, and Cancer treatment and research trust (CTRT), outside the submitted work. The other authors have no conflicts of interest to declare.

Ethical Statement: The authors are accountable for all aspects of the work in ensuring that questions related to the accuracy or integrity of any part of the work are appropriately investigated and resolved. The study was conducted in accordance with the Declaration of Helsinki (as revised in 2013). The study was approved by the institutional review board (Lister Hospital, \#17149) and individual consent for this retrospective analysis was waived.

Open Access Statement: This is an Open Access article distributed in accordance with the Creative Commons Attribution-NonCommercial-NoDerivs 4.0 International License (CC BY-NC-ND 4.0), which permits the noncommercial replication and distribution of the article with the strict proviso that no changes or edits are made and the original work is properly cited (including links to both the formal publication through the relevant DOI and the license). See: https://creativecommons.org/licenses/by-nc-nd/4.0/.

\section{References}

1. Klinger ME. Secondary tumors of the genito-urinary tract. J Urol 1951;65:144-53.

2. Bates AW, Baithun SI. Secondary neoplasms of the bladder are histological mimics of nontransitional cell primary tumours: clinicopathological and histological features of 282 cases. Histopathology 2000;36:32-40.

3. Abrams HL, Spiro R, Goldstein N. Metastases in carcinoma; analysis of 1000 autopsied cases. Cancer 1950;3:74-85.

4. Velcheti V, Govindan R. Metastatic cancer involving bladder: a review. Can J Urol 2007;14:3443-8.

5. Morichetti D, Mazzucchelli R, Lopez-Beltran A, et al. Secondary neoplasms of the urinary system and male genital organs. BJU Int 2009;104:770-6.

6. Melicow MM. Tumors of the urinary bladder: a clinicopathological analysis of over 2500 specimens and biopsies. J Urol 1955;74:498-521.
7. Sheehan EE, Greenberg SD, Scott R. Metastatic Neoplasms of the Bladder. J Urol 1963;90:281-4.

8. Amin MB, Trpkov K, Lopez-Beltran A, et al. Best practices recommendations in the application of immunohistochemistry in the bladder lesions: report from the International Society of Urologic Pathology consensus conference. Am J Surg Pathol 2014;38:e20-34.

9. Epstein JI, Egevad L, Humphrey PA, et al. Best practices recommendations in the application of immunohistochemistry in the prostate: report from the International Society of Urologic Pathology consensus conference. Am J Surg Pathol 2014;38:e6-19.

10. Xiao GQ, Chow J, Unger PD. Metastatic tumors to the urinary bladder: clinicopathologic study of 11 cases. Int J Surg Pathol 2012;20:342-8.

11. Gill HS, Dhillon HK, Woodhouse CR. Adenocarcinoma of the urinary bladder. Br J Urol 1989;64:138-42.

12. Velcheti V, Govindan R. Metastatic cancer involving bladder: a review. Can J Urol 2007;14:3443-8.

13. Sanguedolce F, Landriscina M, Ambrosi A, et al. Bladder Metastases from Breast Cancer: Managing the Unexpected. A Systematic Review. Urol Int 2018;101:125-131.

14. Lin WC, Chen JH: Urinary bladder metastasis from breast cancer with heterogeneic expression of estrogen and progesterone receptors. J Clin Oncol 2007;25:4308-10.

15. Ganem EJ, Batal JT. Secondary malignant tumors of the urinary bladder metastatic from primary foci in distant organs. J Urol 1956;75:965-72.

16. Dobruch J, Daneshmand S, Fisch M, et al. Gender and Bladder Cancer: A Collaborative Review of Etiology, Biology, and Outcomes. Eur Urol 2016;69:300-10.

17. Jayadevappa R, Chhatre S, Wong YN. Comparative effectiveness of prostate cancer treatments for patientcentered outcomes. Medicine (Baltimore) 2017;96:e6790.

18. Feldman A, Borak S, Rais-Bahrami S et al. Secondary Malignancies of the Bladder: Avoiding the Diagnostic Pitfall. Int J Surg Pathol 2018;26:120-5.

19. Cardoso F, Spence D, Mertz S, et al. Global analysis of advanced/metastatic breast cancer: Decade report (20052015). Breast 2018;39:131-8.

20. Aghajanian C, Goff B, Nycum LR, et al. Final overall survival and safety analysis of OCEANS, a phase 3 trial of chemotherapy with or without bevacizumab in patients with platinum-sensitive recurrent ovarian cancer. Gynecol Oncol 2015;139:10-6.

21. Burger R, Enserro D, Tewari K et al. Final overall survival (OS) analysis of an international randomized trial 
evaluating bevacizumab (BEV) in the primary treatment of advanced ovarian cancer. J Clin Oncol 2019;37:2317-28.

22. Elia G, Stewart S, Makhuli ZN, et al. Metastatic

Cite this article as: El-Taji O, Al-Mitwalli A, Malik F, Agarwal S, Gogbashian A, Hughes R, Vasdev N, Sharma A. Secondary neoplasms of the urinary bladder-clinical management and oncological outcomes. Transl Androl Urol 2021;10(6):2427-2434. doi: $10.21037 /$ tau-20-955 breast cancer diagnosed during a work-up for urinary incontinence: a case report. Int Urogynecol J Pelvic Floor Dysfunct 1999;10:39-42. 
Appendix 1 Complete patient management and individual survival for patients with secondary neoplasms of the bladder from each primary malignancy

Prostate

\begin{tabular}{|c|c|c|c|c|c|c|c|c|c|c|c|c|c|}
\hline \multirow[b]{2}{*}{ Patient } & \multirow[b]{2}{*}{$\begin{array}{c}\text { Time between primary diagnosis } \\
\text { and secondary (days) }\end{array}$} & \multirow[b]{2}{*}{ PS } & \multirow[b]{2}{*}{$\begin{array}{l}\text { Method of } \\
\text { spread }\end{array}$} & \multirow[b]{2}{*}{$\begin{array}{l}\text { Other Mets/extent } \\
\text { of disease }\end{array}$} & \multicolumn{4}{|c|}{ Treatment at initial diagnosis of Prostate Cancer } & \multicolumn{4}{|c|}{ Treatment following diagnosis of bladder secondary neoplasm } & \multirow[b]{2}{*}{ Survival (Days) } \\
\hline & & & & & Surgery & $\begin{array}{l}\text { Chemotherapy (Number } \\
\text { of cycles) }\end{array}$ & Radiotherapy & Other & Surgery & $\begin{array}{l}\text { Chemotherapy } \\
\text { (Number of cycles) }\end{array}$ & Radiotherapy & Other & \\
\hline 1 & 0 & 1 & Direct & Bone, Lymph & n/a & n/a & n/a & $\mathrm{n} / \mathrm{a}$ & - & Docetaxel (3 cycles) & $\begin{array}{l}21 \text { Gy in three } \\
\text { fractions }\end{array}$ & ADT & 654 \\
\hline 3 & 1693 & 1 & Direct & Bone, Lymph & Open Prostatectomy & $\mathrm{n} / \mathrm{a}$ & $\begin{array}{l}70 \text { Gy in } 35 \\
\text { fractions }\end{array}$ & $\mathrm{n} / \mathrm{a}$ & - & Docetaxel (6 cycles) & $\begin{array}{l}21 \text { Gy in three } \\
\text { fractions }\end{array}$ & ADT & 1250 \\
\hline 4 & 0 & 3 & Direct & Lymph, bone & $n / a$ & $n / a$ & n/a & $\mathrm{n} / \mathrm{a}$ & - & - & - & ADT & 259 \\
\hline 5 & 0 & 2 & Direct & Bone, Lymph, Lung & $n / a$ & $n / a$ & $n / a$ & $\mathrm{n} / \mathrm{a}$ & - & - & $\begin{array}{l}21 \text { Gy in three } \\
\text { fractions }\end{array}$ & ADT & 632 \\
\hline 6 & 0 & 4 & Direct & Lymph & $n / a$ & $\mathrm{n} / \mathrm{a}$ & $n / a$ & $\mathrm{n} / \mathrm{a}$ & - & - & - & ADT & 77 \\
\hline 7 & 4388 & 2 & Direct & Lymph & $n / a$ & $n / a$ & $\begin{array}{l}70 \text { Gy in } 35 \\
\text { fractions }\end{array}$ & $\mathrm{n} / \mathrm{a}$ & - & Docetexal (6 cycles) & - & ADT & 1489 \\
\hline 8 & 0 & 2 & Direct & Lymph, bone & $\mathrm{n} / \mathrm{a}$ & $n / a$ & $n / a$ & $\mathrm{n} / \mathrm{a}$ & - & Docetexal (6 cycles) & $\begin{array}{l}21 \text { Gy in three } \\
\text { fractions }\end{array}$ & ADT & 1407 \\
\hline 9 & 0 & 1 & Direct & Lymph, bone & $n / a$ & $n / a$ & $\mathrm{n} / \mathrm{a}$ & $\mathrm{n} / \mathrm{a}$ & - & Docetexal (6 cycles) & $\begin{array}{l}21 \text { Gy in three } \\
\text { fractions }\end{array}$ & ADT & 961 \\
\hline 10 & 0 & 3 & Direct & Lymph & $n / a$ & $n / a$ & $n / a$ & $\mathrm{n} / \mathrm{a}$ & - & - & - & ADT & 210 \\
\hline 11 & 948 & 3 & Direct & Lymph, Bone, Lung & n/a & n/a & $\begin{array}{l}70 \text { Gy in } 35 \\
\text { fractions }\end{array}$ & ADT & - & - & - & ADT & 154 \\
\hline
\end{tabular}

Complete patient management and individual survival for patients with secondary neoplasms of the bladder from a primary prostate malignancy. ADT- androgen deprivation therapy.

Colorectal

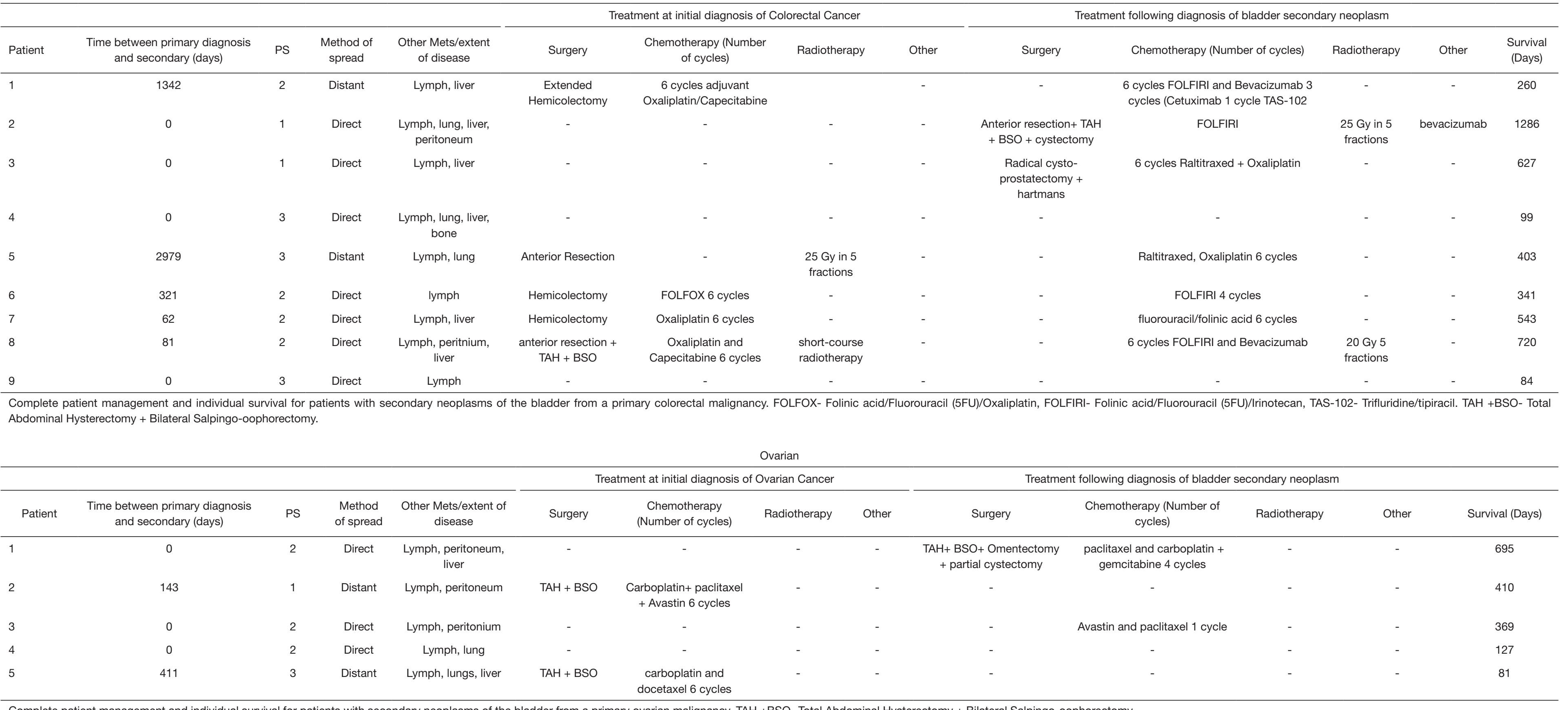

Complete patient management and individual survival for patients with secondary neoplasms of the bladder from a primary ovarian malignancy. TAH +BSO- Total Abdominal Hysterectomy + Bilateral Salpingo-oophorectomy. 
Cervical

Treatment at initial diagnosis of Cervical Cancer $\quad$ Treatment following diagnosis of bladder secondary neoplasm

\begin{tabular}{|c|c|c|c|c|c|c|c|c|c|c|c|c|c|}
\hline Patient & $\begin{array}{l}\text { Time between primary diagnosis } \\
\text { and secondary (days) }\end{array}$ & PS & $\begin{array}{l}\text { Method of } \\
\text { spread }\end{array}$ & $\begin{array}{l}\text { Other Mets/extent of } \\
\text { disease }\end{array}$ & Surgery & $\begin{array}{l}\text { Chemotherapy (Number } \\
\text { of cycles) }\end{array}$ & Radiotherapy & Other & Surgery & Chemotherapy (Number of cycles) & Radiotherapy & Other & Survival (Days) \\
\hline 1 & 241 & 3 & Direct & Lymph, liver & - & Cisplatin 2 cycles & 20 Gy 5 fractions & - & - & - & - & - & 125 \\
\hline 2 & 324 & 2 & Direct & Lymph, rectum & $\mathrm{TAH}+\mathrm{BSO}$ & Cisplatin 6 cycles & 20 Gy 5 fractions & & - & Cisplatin +paclitaxel 3 cycle & 20 Gy 5 fractions & & 236 \\
\hline 3 & 0 & 3 & Direct & Lymph, rectum & - & - & - & - & - & $\begin{array}{l}\text { Cisplatin not tolerated then } \\
\text { gemcitabine } 1 \text { cycle }\end{array}$ & 20 Gy 5 fractions & & 162 \\
\hline 4 & 0 & 3 & Direct & Lymph, rectum, Liver & - & - & - & - & - & - & - & & 134 \\
\hline
\end{tabular}

Complete patient management and individual survival for patients with secondary neoplasms of the bladder from a primary cervical malignancy. TAH +BSO- Total Abdominal Hysterectomy + Bilateral Salpingo-oophorectomy.

Breast

\begin{tabular}{|c|c|c|c|c|c|c|c|c|c|c|c|c|c|}
\hline \multirow[b]{2}{*}{ Patient } & \multirow[b]{2}{*}{$\begin{array}{l}\text { Time between primary diagnosis } \\
\text { and secondary (days) }\end{array}$} & \multirow[b]{2}{*}{ PS } & \multirow[b]{2}{*}{$\begin{array}{l}\text { Method of } \\
\text { spread }\end{array}$} & \multirow[b]{2}{*}{ Other Mets/ extent of disease } & \multicolumn{4}{|c|}{ Treatment at initial diagnosis of Breast Cancer } & \multicolumn{4}{|c|}{ Treatment following diagnosis of bladder secondary neoplasm } & \multirow[b]{2}{*}{ Survival (Days) } \\
\hline & & & & & Surgery & $\begin{array}{l}\text { Chemotherapy (Number of } \\
\text { cycles) }\end{array}$ & Radiotherapy & Other & Surgery & $\begin{array}{c}\text { Chemotherapy } \\
\text { (Number of cycles) }\end{array}$ & Radiotherapy & Other & \\
\hline 1 & 1869 & 1 & Distant & Bone, Lymph, Liver, Brain, Lung & Mastectomy & FEC+ paclitaxel 6 cycles & Radiotherapy & trastuzumab & - & docetaxel & - & Pertuzumab+ Trastuzumab+ & 241 \\
\hline 2 & 1211 & 2 & Distant & Lymph, Bone, Liver & Mastectomy & FEC + Docetaxel 6 cycles & Radiotherapy & - & - & - & - & Anastrazole & 162 \\
\hline 3 & 481 & 2 & Distant & Lymph, Liver, Lung & Mastectomy & FEC + Docetaxel 6 cycles & Radiotherapy & Trastuzumab & - & Paclitaxel & - & Trastuzumab & 369 \\
\hline
\end{tabular}

Complete patient management and individual survival for patients with secondary neoplasms of the bladder from a primary breast malignancy. FEC- 5 fluorouracil (5FU) Epirubicin, Cyclophosphamide.

Lymphoma

\begin{tabular}{|c|c|c|c|c|c|c|c|c|c|c|c|c|c|}
\hline \multirow[b]{2}{*}{ Patient } & \multirow[b]{2}{*}{$\begin{array}{l}\text { Time between primary diagnosis and } \\
\text { secondary (days) }\end{array}$} & \multirow[b]{2}{*}{ PS } & \multirow[b]{2}{*}{ Method of spread } & \multirow[b]{2}{*}{$\begin{array}{l}\text { Other Mets/extent of } \\
\text { disease }\end{array}$} & \multicolumn{4}{|c|}{ Treatment at initial diagnosis of Lymphoma } & \multicolumn{4}{|c|}{ Treatment following diagnosis of bladder secondary neoplasm } & \multirow[b]{2}{*}{ Survival (Days } \\
\hline & & & & & Surgery & $\begin{array}{l}\text { Chemotherapy (Number } \\
\text { of cycles) }\end{array}$ & Radiotherapy & Other & Surgery & $\begin{array}{l}\text { Chemotherapy (Number of } \\
\text { cycles) }\end{array}$ & Radiotherapy & Other & \\
\hline 1 & 146 & 3 & hematopoietic & Spleen, Liver & - & - & - & - & - & - & - & - & 98 \\
\hline 2 & 431 & 2 & hematopoietic & Bone marrow, Lung & - & - & - & - & - & - & - & - & 145 \\
\hline 3 & 368 & 2 & hematopoietic & Lung, Liver & - & $\mathrm{CHOP}+$ Methotrexate & - & - & - & - & - & - & 278 \\
\hline
\end{tabular}

Complete patient management and individual survival for patients with secondary neoplasms of the bladder from a primary Iymphoma. CHOP- Cyclophosphamide, Doxorubicin (Adriamycin), Vincristine (Oncovin), Prednisolone.

Renal

\begin{tabular}{|c|c|c|c|c|c|c|c|c|c|c|c|c|c|}
\hline \multirow[b]{2}{*}{ Patient } & \multirow[b]{2}{*}{$\begin{array}{c}\text { Time between primary diagnosis and } \\
\text { secondary (days) }\end{array}$} & \multirow[b]{2}{*}{ PS } & \multirow[b]{2}{*}{ Method of spread } & \multirow[b]{2}{*}{$\begin{array}{l}\text { Other Mets/extent of } \\
\text { disease }\end{array}$} & \multicolumn{4}{|c|}{ Treatment at initial diagnosis of Renal Cell Carcinoma } & \multicolumn{4}{|c|}{ Treatment following diagnosis of bladder secondary neoplasm } & \multirow[b]{2}{*}{ Survival (Days) } \\
\hline & & & & & Surgery & $\begin{array}{l}\text { Chemotherapy (Number } \\
\text { of cycles) }\end{array}$ & Radiotherapy & Other & Surgery & $\begin{array}{l}\text { Chemotherapy } \\
\text { (Number of cycles) }\end{array}$ & Radiotherapy & Other & \\
\hline 1 & 744 & 2 & Distant & Liver, Lung & Radical Nephrectomy & - & - & - & - & - & - & - TKI & 326 \\
\hline 2 & 3868 & 0 & Distant & Lung & Radical Nephrectomy & - & - & - & - & - & - & TKI & 1383 \\
\hline
\end{tabular}

Complete patient management and individual survival for patients with secondary neoplasms of the bladder from a primary renal malignancy. TKI- Tyrosine Kinase Inhibitor.

Gastric

\begin{tabular}{|c|c|c|c|c|c|c|c|c|c|c|c|c|c|}
\hline & & & & & & Treatment at initial diagnosis & f Gastric Cance & & Treatmer & ollowing diagnosis of bladd & r secondary nec & & \\
\hline Patient & $\begin{array}{l}\text { Time between primary diagnosis and } \\
\text { secondary (days) }\end{array}$ & PS & Method of spread & $\begin{array}{l}\text { Other Mets/extent of } \\
\text { disease }\end{array}$ & Surgery & $\begin{array}{l}\text { Chemotherapy (Number of } \\
\text { cycles) }\end{array}$ & Radiotherapy & Other & Surgery & $\begin{array}{l}\text { Chemotherapy (Number } \\
\text { of cycles) }\end{array}$ & Radiotherapy & Other & Survival (Days) \\
\hline 1 & 0 & 2 & Distant & Liver, Bone & - & - & - & - & - & $\begin{array}{l}\text { epirubicin, cisplatin, and } \\
\text { fluorouracil } 1 \text { cycle }\end{array}$ & - & - & 98 \\
\hline 2 & 0 & 3 & Distant & Liver, Peritonium, Lung & - & - & - & - & - & - & - & - & 31 \\
\hline
\end{tabular}

Complete patient management and individual survival for patients with secondary neoplasms of the bladder from a primary gastric malignancy. 